\title{
Análise da ocorrência de leishmaniose tegumentar americana através de imagem obtida por sensoriamento remoto orbital em localidade urbana da região Sudeste do Brasil*
}

\author{
Analysis of the occurrence of american cutaneous leishmaniasis in \\ Brazil by remote sensing satellite imagery
}

\author{
Cristina Miranda, José L. Massa e Cristiano C.A. Marques \\ Universidade do Vale do Paraíba. São José dos Campos, SP - Brasil (C.M.); Instituto Nacional de \\ Pesquisas Espaciais. São José dos Campos, SP - Brasil (J.L.M.); Superintendência de Controle de \\ Endemias. São Paulo, SP - Brasil (C.C.A.M.)
}

\section{Resumo}

As áreas onde, segundo notificação, ocorreram casos de leishmaniose tegumentar americana, na região de Lagoinha, Estado de São Paulo, Brasil (Lat 2305 S; Lon 45 11), nos anos de 1993 e 1994, foram localizadas numa imagem do satélite TM-LANDSAT. A composição colorida artificial feita com as bandas 3, 4 e 5 da imagem permitiu a identificação de vegetação arbustiva, ou dentro mesmo dos limites indicados para aquelas localidades ou à distância máxima de cerca de 250 metros do perímetro de cada área. A utilização de um recurso capaz de possibilitar uma visão mais abrangente de uma área geográfica tornou evidente as vantagens do sensoriamento remoto orbital para o estudo desta endemia.

Leishmaniose mucocutânea, epidemiologia. Controle de mosquitos. Monitoramento ambiental.

\section{Abstract}

The areas in which american cutaneous leishmaniasis was reported in 1993 and 1994 for the region around the town of Lagoinha, S. Paulo, Brazil (Lat $23^{\circ}$ $05^{\prime} S$; Long $45^{\circ} 11 \mathrm{w}$ ) were plotted on a TM-LANDSAT image. The false color composition of bands 3, 4 and 5 made it possible to identify the relevant vegetation (shrubs and trees) within the boundaries of those areas and in their proximity, where they were found at a distance of not more than about 250

\footnotetext{
* Subvencionado pela FAPESP (Processos nºs 92/0799-0, 93/1083-1 e 94/0321-9).

Correspondência para/Correspondence to: José L. Massa - Instituto Nacional de Pesquisas Espaciais/INPE - Av. dos Astronautas, 1758 - $12227-010$ São José dos Campos, SP - Brasil. Fax: (012) 323.1181 E-mail: massa@ltid.inpe.br

Edição subvencionada pela FAPESP. Processo 95/2290-6.

Recebido em 14.12.1995. Aprovado em 1.4.1996.
} 
meters from the perimeter of each area. The use of means capable of presenting a larger view of a geographical area made the advantages of remote satellite sensing as a tool for the study of this endemic disease clear.

Leishmaniasis, mucocutaneous, epidemiology. Mosquito control. Environmental monitoring.

\section{INTRODUÇÃO}

A leishmaniose tegumentar americana constitui importante problema de saúde pública em vários Estados brasileiros e, longe de estar controlada, encontra-se em franca expansão. Na década de 50 houve uma diminuição geral da ocorrência de casos, porém este número vem crescendo progressivamente nos últimos 20 anos, observando-se surtos epidêmicos em várias regiões do País (Pereira e Fonse$\mathrm{ca}^{9}$,1994).

Os métodos atuais de controle da doença são restritos ao ambiente peridoméstico e têm se mostrado inadequados (Alexander e col. ${ }^{1}, 1995$; Sessa e col. ${ }^{12}$, 1994). As metodologias de controle, preconizadas para uma outra situação de distribuição populacional, não acompanharam a demanda gerada pela taxa de crescimento e pela crescente ocupação das áreas de risco para a doença. Associado a isto, um percentual relativamente alto de formas subclínicas foi detectado em indivíduos que vivem em algumas áreas de risco, o que dificulta a própria determinação dessas áreas (Marzochi e Marzochi ${ }^{7}, 1994$ ). Acresce ainda que a ausência de recursos financeiros para as atividades de prevenção e controle tem impedido o desenvolvimento técnico-científico e a formação de recursos humanos nessa área.

A distribuição da principal espécie incriminada como vetora da leishmaniose, Lutzomia intermedia, é muito ampla e não está suficientemente estudada para explicar a distribuição da doença. Esta espécie é encontrada em vários Estados brasileiros, inclusive em São Paulo (Marzochi e Marzochi ${ }^{7}, 1994$ ), onde prevalece a transmissão em ambientes alterados, associados à vegetação secundária (matas) e reservatórios sinantrópicos. É encontrada também na Argentina (Salomon e col. $\left.{ }^{11}, 1995\right)$ e Paraguai (Souza e col. $\left.{ }^{13}, 1994\right)$.

Percebem-se pois, face às dificuldades nas tentativas de controle da doença, as possíveis vantagens da utilização de recursos capazes de possibilitar uma visão mais abrangente da ocorrência e distribuição dos casos de leishmaniose.
A aplicação de técnicas e produtos de sensoriamento remoto em estudos epidemiológicos teve início nos primeiros anos da década de 70, segundo Hugh-Jones $^{4}$, 1989. Em seu artigo de revisão, esse autor ressalta as vantagens do seu uso, não como uma solução universal, mas como uma ferramenta para a elaboração de novas questões e soluções.

Um exemplo de identificação de um habitat e da delimitação da sua área utilizando-se sensoriamento remoto orbital pode ser observado no estudo sobre a febre do Vale do Rift, no Kenya, na Africa. A partir da verificação da ocorrência de uma quantidade desses habitats numa área geográfica menor foi possível, com um esforço adicional relativamente pequeno, examinar uma área muito mais extensa, na busca bem sucedida de réplicas da microregião inicialmente percebida e caracterizada (Pope e col. ${ }^{10}$, 1992; Linthicum e col. ${ }^{6}$, 1987).

O uso de sensoriamento remoto também tem sido valioso em escala regional para identificar tipos de vegetação e monitorar a variabilidade temporal e espacial das características da vegetação. A partir desses dados, podem ser determinados habitats de mosquitos. Hayes e col. ${ }^{3}$ (1985), enfatizam que métodos de controle de mosquitos (exceto pelo tratamento químico de mosquitos adultos, impraticável em ambientes florestais) geralmente requerem conhecimento da localização, das características e medidas da extensão desses locais, habitats larvários potenciais. Nesse sentido, vários autores abordam correlações entre as características ambientais e os fatores determinantes do grau de risco para doenças endêmicas. Wood e col. ${ }^{15}$ (1992), combinaram medidas de refletância obtidas por sensoriamento remoto durante $o$ desenvolvimento da cobertura vegetal com medidas de distâncias entre arrozais e pastagens (fontes de alimentação sangüínea para os mosquitos), num sistema de informações geográficas. Em seu citado trabalho puderam distinguir arrozais com maior ou menor capacidade de servirem como criadouros de mosquitos.

A relação entre parâmentros ambientais, tais como vegetação e água com habitats larvários, atra- 
vés de modelo conceitual, ilustrada no trabalho de Wood e col. ${ }^{15}$, demonstra que os dados de sensoriamento remoto orbital e um SIG-Sistema de Informações Geográficas podem ser usados para identificar, caracterizar e monitorar muitos destes mesmos parâmetros ambientais. Com isso pode-se prever a evolução dos padrões espaciais e temporais e sua associação com os habitats larvários.

Os Centros de Pesquisas Ames e Lewis, da NASA, colaboraram com o SPRL - Space Physics Research Laboratory, da Universidade de Michigan, em Ann Arbor, MI, USA, no estudo interdisciplinar de um sistema dotado de satélite exclusivo, conhecido por Projeto MEDSAT. Pretende-se que o MEDSAT seja um satélite capaz de observar as condições ambientais, e integrando-as com outras informações determine o grau de risco para doenças transmissíveis por vetores numa dada área geográfica (Vesecky $\left.{ }^{14}, 1991\right)$.

É sabido que os flebotomíneos alados são insetos que em geral possuem pouca tendência a se afastarem dos seus abrigos naturais, embora este seja um assunto controverso. Em casos exepcionais foi detectada dispersão de até $1.500 \mathrm{~m}$, mas em geral ela não passa de 200 a 500 m (Forattini ${ }^{2}$,1973), o que abre uma perspectiva razoável de estudo, utilizandose geoprocessamento e sensoriamento remoto, sobre a associação entre ocorrências de casos da doença e presença de vegetação arbórea, ou seja, diferente de campo antrópico.

O presente trabalho consiste em analisar a distribuição dos casos de leishmaniose notificados pelas autoridades sanitárias no Município de Lagoinha, Estado de São Paulo, procurando uma associação entre a ocorrência de casos da doença e o ambiente próximo, com o auxílio de produtos e técnicas de sensoriamento remoto orbital.

\section{MATERIAL E MÉTODO}

\section{Dados de Sensoriamento Remoto}

Sensoriamento remoto pode ser definido como sendo a utilização conjunta de sensores e equipamentos para processamento de dados, entre outros, com o objetivo de estudar o ambiente terrestre através do registro e análise das interações entre a radiação eletromagnética e as substâncias que compõem a superfície terrestre (Novo $\left.{ }^{8}, 1989\right)$.

Cada item na natureza tem uma distribuição de radiação refletida, emitida e absorvida, que pode ser usada para a diferenciação entre os itens e obter informação sobre seus formatos, tamanhos e até sobre algumas de suas características físicas e químicas.
O sistema LANDSAT é composto até o momento de uma série de 5 satélites. Este sistema foi desenvolvido pela National Aeronautics and Space Administration (NASA). O LANDSAT-5 está a uma altura de $705 \mathrm{~km}$ em relação à superfície terrestre no Equador e recobre a superfície da terra a cada 16 dias. O sensor a bordo, o Thematic Mapper - TM, é um sistema avançado de varredura multiespectral e tem uma resolução do terreno de $30 \mathrm{~m}$ e 7 bandas espectrais.

A luz do sol refletida da terra, nas suas várias bandas ou faixas de frequiência, é captada através de um sistema óptico dotado de uma câmara CCD - "Charge-Coupled Device", que é o transdutor ou sensor propriamente dito. Nela, a cada varredura, são captados os sinais luminosos provenientes dos pixels ("picture elements" ou células de resolução), situados no solo e gerados os correspondentes sinais elétricos.

A banda 3 inclui comprimentos de onda que variam de $0,63 \mu \mathrm{m}$ a $0,69 \mu \mathrm{m}$, na região correspondente ao vermelho da faixa visível do espectro eletromagnético. A banda 4 inclui comprimentos de onda que variam de 0,76 $\mu \mathrm{m}$ a $0,90 \mu \mathrm{m}$, na região do infravermelho próximo. E a banda 5 inclui comprimentos de onda que variam de 1,55 $\mu \mathrm{m}$ a $1,75 \mu \mathrm{m}$, na região do infravermelho médio.

O Sistema de Recepção de Dados de Satélite é constituído de uma Estação de Recepção, implantada em Cuiabá, onde os dados são recebidos através de uma antena parabólica e gravados em fitas magnéticas de alta densidade (High Density Digital Magnetic Tape - HDDT). Estas fitas são enviadas para o Instituto Nacional de Pesquisas Espaciais (INPE) - Cachoeira Paulista, onde está localizado o laboratório de processamento eletrônico e fotográfico. Os dados recebidos são, então, transformados em imagens fotográficas ou gravados em fitas magnéticas adequadas para utilização com os computadores (Computer Compatible Tapes - CCT).

As imagens TM-LANDSAT são digitalizadas, ou seja, transformadas em dados digitais em 256 diferentes níveis de cinza. Esses 256 valores variam de 0 a 255 e são codificados em 8 bits (1 byte). Desta maneira, para cada "pixel" da imagem corresponde um valor de nível de cinza.

A imagen orbital utilizada no presente trabalho, produto do sensor múltiplo do LANDSAT, foi adquirida na forma digital, com nível de correção PL-5 (Processing Level-5), junto ao INPE. Refere-se à órbita ponto 218/ 76X, de 24 de setembro de 1989, nas bandas TM3, TM4 e TM5.

Através de um processador de mapas - Map II, que constitui um tipo de SIG (Sistema de Informações Geográficas) operando num computador Macintosh Quadra950, foi feito o registro da imagem com uma carta do município de Lagoinha, na escala 1:50000, digitalizada opticamente por um instrumento de varredura eletro óptico mecânico ("scanner").

Com o objetivo de facilitar a identificação dos temas realizou-se uma operação para produzir composição colorida artificial das bandas 3, 4 e 5 da imagem TMLANDSAT (Fig. 1). 


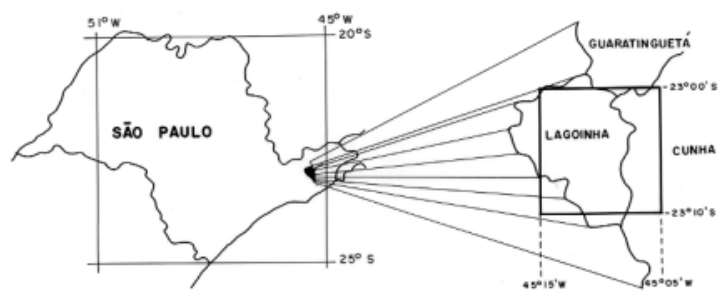

Figura 1 - Localização da área de estudo, Município de Lagoinha, SP.

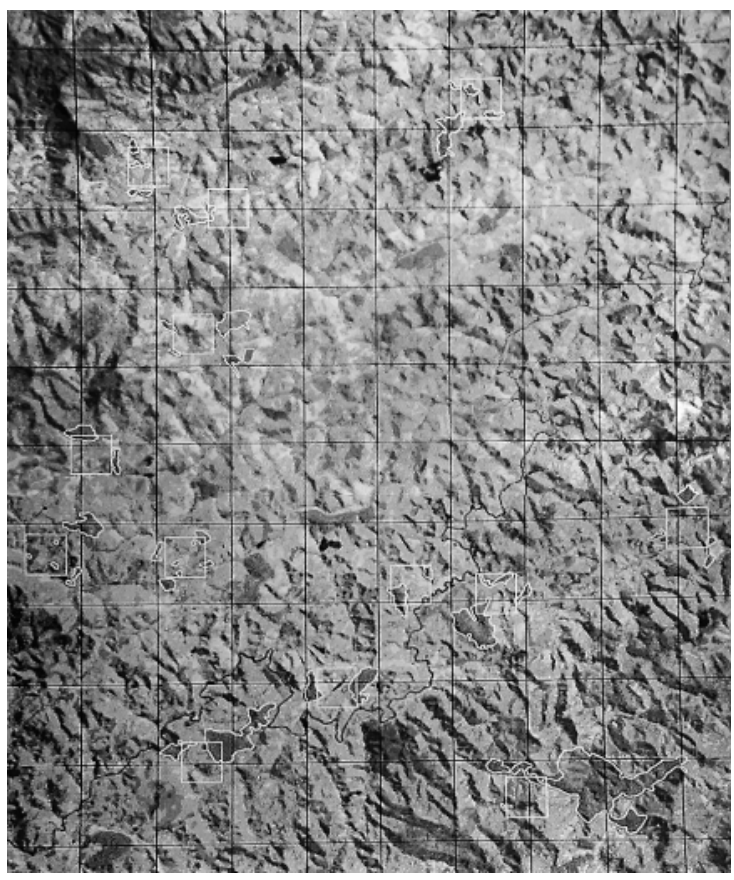

Figura 2 - Composição artificial das bandas 3, 4 e 5 TMLANDSAT, evidenciando localidades onde os casos foram notificados e a vegetação arbustiva próxima. Trata-se de uma área retangular compreendida entre os paralelos $23^{\circ} 00^{\prime} \mathrm{S}$ e $23^{\circ} 10^{\prime}$ $\mathrm{S}$ e entre os meridianos $45^{\circ} 05^{\prime} \mathrm{W}$ e $45^{\circ} 15^{\prime} \mathrm{W}$.

\section{Área de Estudo}

Os esforços para caracterizar as áreas com potencial de transmissão da leishmaniose centralizaram-se sobre propriedades particulares onde, em 1993 e 1994, vários casos da doença foram registrados pelo Centro de Saúde do Município de Lagoinha, e estão relacionados na Tabela. A localização da região onde ocorreram estes casos é indicada na Figura 2.

A determinação, na imagem, daquelas localidades, foi possibilitada através da consideração de elementos da toponímia, tais como o Rio Paraitinga e estradas vicinais, além da vegetação característica e dados de GPS (Global Positioning System), obtidos nas localidades visitadas. O GPS pode fornecer as coordenadas geográficas dos pontos de observação com precisão melhor que um segundo de arco.
Tabela - Casos autóctones de leishmaniose tegumentar americana notificados, por localidade, no Município de Lagoinha, SP, nos anos de 1993 e 1994.

\begin{tabular}{lcc}
\hline & \multicolumn{2}{c}{$N^{\circ}$ de Casos } \\
Localidade & 1994 & 1995 \\
\hline Santa Rita & 1 & 2 \\
Itaim & 0 & 5 \\
Catioquinha & 0 & 1 \\
Faxinal & 1 & 2 \\
Barro Vermelho & 0 & 2 \\
Palhinha & 2 & 2 \\
Fazenda Cristal & 0 & 1 \\
Fazenda Fortaleza & 0 & 1 \\
Jaboticatuba & 1 & 0 \\
Brejauva & 1 & 0 \\
Imbiri & 1 & 0 \\
Rio do Peixe & 0 & 1 \\
Tapera & 0 & 2 \\
\hline Total & 7 & 19 \\
\hline
\end{tabular}

Fonte: SUCEN - Superintendência de Controle de Endemias, Secretaria Estadual de Saúde, 1995.

\section{RESULTADOS}

As localidades onde os indivíduos que contraíram a doença residiam e/ou trabalhavam estão marcadas na Figura 2 com um quadrado de 918 metros de lado e as áreas de vegetação nas proximidades foram contornadas.

A imagem resultante da operação combinando as bandas 3, 4 e 5 numa única composição colorida artificial possibilitou identificar a vegetação arbórea presente nas localidades demarcadas e próximas a elas. Com isto, foi possível visualizar o aspecto de toda a área e a distribuição espacial da vegetação nas localidades consideradas.

A presença de vegetação arbustiva pode ser notada em todas as localidades, ou dentro mesmo dos limites indicados para as mesmas ou à distância máxima de cerca de $250 \mathrm{~m}$. Não foram visitadas todas as localidades demarcadas, mas em duas delas, que apresentam inclusive ambientes claramente similares, Palhinha e Fazenda Cristal, a distância das residências e/ou locais de trabalho à borda da mata é de cerca de 60 e 80 metros, respectivamente.

\section{DISCUSSÃO}

A combinação de dados espaciais e informações obtidas através de observações in loco foi usada para visualizar a distribuição de locais de ocorrência da leishmaniose e, portanto, dos ambientes onde possi- 
velmente ocorreu a interação do homem com o ciclo silvestre da doença.

A observação isolada e comparativa dessas áreas onde foram registrados casos da doença (locais de trabalho e/ou residências de indivíduos infectados) pode se mostrar de valor prático. Em primeiro lugar porque elas poderão abranger os criadouros e segundo porque poderão se provar áreas de risco, de caracterização mais fácil e menos custosa e, ainda assim, de utilidade para o exame e avaliação, quanto ao risco, da área de todo o município.

\section{REFERÊNCIAS BIBLIOGRÁFICAS}

\section{ALEXANDER, B.; JARAMILLO, C.; USMA, M.C.;} QUESADA, B.L.; CADENA, H.; ROA, W.; TRAVI, B.L. An attempt to control phlebotominae sand flies (Diptera: Psychodidae) by residual spraying with deltamethrin in a Colombian village. Mem. Inst. Oswaldo Cruz, 90: 421-4, 1995.

2. FORATTINI, O.P. Entomologia médica: Psychodidae. São Paulo, Ed.Univ. São Paulo, 1973, v. 4, p 180.

3. HAYES, R.O.; MAXWELL, E.L.; MITCHELL, C.J.; WOODZICK,T.L. Detection, identification, and classification of mosquito larval habitats using remote sensing scanners in earth-orbiting satellites. Bull. World Health Organ., 63: 361-74, 1985.

4. HUGH-JONES, M.E. Aplications of remote sensing to the identification of the habitats of parasites and disease vectors. Parasitol. Today, 5: 244-51, 1989.

5. KILLICK-KENDRICK, R. New strategies for control forum: vector control.In: Leishmaniasis: the current status and new strategies for control. London, D.T Hart, King's College London, 1989. p. 821-2.

6. LINTHICUM, K.; BAILEY, C.L.; DAVIES, F.G.;TUCKER, C.J. Detection of Rift Valley fever viral activity in Kenya by satellite remote sensing imagery. Science, 235: 1656-9, 1987.

7. MARZOCHI, M.C.A. \& MARZOCHI, K.B.F. Tegumentary and viceral leishmaniases in Brazil: emerging anthropozoonosis and possibilities of their control. Cad. Saúde Pública, 10: 357-75, 1994.

8. NOVO, E.M.L.M. Sensoriamento remoto: princípios e aplicações. São Paulo, Edgard Blücher, 1989.
As dificuldades na identificação dos limites geográficos de áreas endêmicas sugerem, segundo Killick-Kendrick ${ }^{5}$ (1989), que é improvável que novas estratégias de controle do vetor da leismaniose para áreas extensas possam ser formuladas sem que investigações criativas sejam utilizadas.

Cabe assinalar, neste ponto, que os satélites a serem lançados no futuro, dotados de sensores aperfeiçoados, maior número de canais (faixas de freqüência de emissão/captação) e melhor resolução, por certo induzirão iniciativas mais ambiciosas.

9. PEREIRA, G.M.F. \& FONSECA, H.H.R. Leishmaniose tegumentar americana: epidemiologia e controle. Rev. Soc. Bras. Med. Trop., 27: 45-50, 1994.

10. POPE, K.O.; SHEFFNER, E.J.; LINTHICUM, K.L.; BAILEY, C.L.; LOGAN, T.M. Identification of Central Kenya Rift Valley fever virus vector habitats with landsat TM and evaluation of their flooding status with airborne imaging radar. Remote Sen. Environ., 40: 185-96, 1992.

11. SALOMON, O.D.; TRAVI, B.L.; SEGURA, E.L. Note on sandflies associated with a tegumentary leshmaniasis focus in Salta, Argentina. Rev. Ins. Med. Trop. S. Paulo, 37: 91-2, 1995.

12. SESSA, P.A.; FALQUETO, A.; VAREJÃO, J.B. Tentativa de controle da leishmaniose tegumentar americana por meio do tratamento dos cães doentes. Cad. Saúde Pública, 10: 457$63,1994$.

13. SOUZA, M.B.; MARZOCHI, M.C.A.; CONCEIÇÃO, N.F. Estudos preliminares da fauna flebotomínica em áreas endêmicas de leishmaniose tegumentar nos departamentos de San Pedro e Alto Paraná, Paraguay. Rev. Soc. Bras. Med. Trop., 27: 115, 1994.

14. VESECKY, J.F. The design of a remote sensing platform for malaria research and control. Ann Arbor, University of Michigan, Aerospace Engineering and Atmospheric, Oceanic and Space Sciences Departments, 1991.

15. WOOD, B.; BECK, L.; WASHINO, R.; HIBBARD,K.; SALUTE, J. Estimating high mosquito producing rice fields using spectral and spatial data. Ames, Research Center, Moffet Field, 1992. [Preprint]. 